
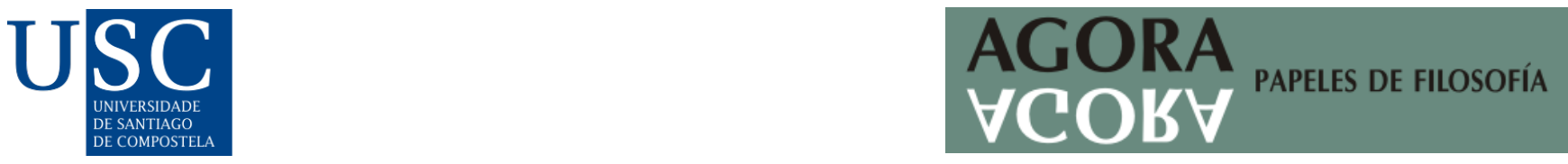

\title{
EL AMOR, LA BELLEZA Y EL 'ETERNO FEMENINO' EN EL FAUSTO DE GOETHE A TRAVÉS DE LOS HEROICOS FURORES DE GIORDANO BRUNO Y LA HYPNEROTOMACHIA POLIPHILI DE COLONNA
}

\author{
Juan Manuel de Faramiñán Fernández-Fígares ${ }^{1 \text { (D) }}$ \\ ${ }^{1}$ Universidad de Granada, España
}

Recibido: 12/03/2021; Aceptado: 30/06/2021

\section{Resumen}

Este artículo analiza la presencia simbólica del amor, la belleza y el 'eterno femenino' en la tragedia Fausto de Johann Wolfgang von Goethe a través de la hermenéutica comparativa con dos textos fundamentales del Renacimiento, De los heroicos furores de Giordano Bruno y la Hypnerotomachia Poliphili de Colonna. La tesis de partida es que los tres amores de Fausto, Margarita, Helena y la Mater Gloriosa, son en realidad una representación simbólica de los tres aspectos fundamentales del alma (físico, psicológico y espiritual) que también podemos encontrar en estos dos textos por su conexión con la tradición neoplatónica.

Palabras clave: Fausto; Goethe; Giordano Bruno; Sueño de Polífilo; Eros; Eterno Femenino

\begin{abstract}
This article analyzes the symbolic presence of love, beauty and the 'eternal feminine' in the tragedy Faust by Johann Wolfgang von Goethe through comparative hermeneutics with two fundamental texts of the Renaissance, The Heroic Enthusiasts by Giordano Bruno and the Hypnerotomachia Poliphili by Colonna. The starting thesis is that the three loves of Faust, Margarete, Helena and the Mater Gloriosa, are actually a symbolic representation of the three fundamental aspects of the soul (physical, psychological and spiritual) that can also be found in these two texts by its connection with the Neoplatonic tradition.
\end{abstract}

Keywords: Faust; Goethe; Giordano Bruno; Polyphile's dream; Eros; Eternal feminine

\section{INTRODUCCIÓN}

Eros, el amor, la belleza y el 'eterno femenino', como símbolos del alma en sus distintos aspectos y expresiones, son conceptos comunes en la filosofía platónica, neoplatónica y hermética. Esta influencia, que alcanza el Renacimiento, se renueva con espíritu innovador en la Alemania de finales del siglo XVIII con escritores, poetas y músicos tales como Goethe, Schiller, Schlegel, Hölderlin, Hoffmann, Beethoven o Schubert, todos ellos adalides del Romanticismo y el Clasicismo alemán. 
En sus obras, el amor, la belleza y la figura de 'lo femenino' adquieren una especial relevancia y envergadura, y comparten una serie de notas características muy señaladas que podemos ver reflejadas de manera muy clara en la tragedia Fausto de Johann Wolfgang von Goethe. No en vano, él mismo reconoce en su autobiografía Poesía y Verdad que su pensamiento se apoya firmemente en el neoplatonismo y el hermetismo (2017, p. 360).

Así, en muchas de sus obras, la figura del amor (Eros) se presenta como un conector entre dos realidades, como un mediador entre 'lo divino' y lo humano, entre las ideas y las formas, entre las esencias y las apariencias. Eros adquiere, de este modo, un perfil serpentino y multiforme, el papel de un guía que se expresa de distinta manera según el grado de conciencia de cada uno, es decir, que su función se adapta a las variadas formas en las que cada ser humano se percibe a sí mismo, a los demás y a la naturaleza, así como al modo en la que cada uno toma conciencia directa de su lugar y posición en el tiempo y en el espacio. Es, en cierto modo, una de las múltiples representaciones del fenómeno primordial (Urphänomen) goethiano de raigambre neoplatónica que impulsa constantemente el movimiento de la naturaleza (Rotten, 1913).

Este aspecto concreto del tema del amor en Goethe podría tener su origen, según Kristeller, en el tratado Sobre el Amor de Ficino (Kristeller, 1964, p. 113), cuya traducción estaba presente en la mayoría de las obras de Plotino y Platón que Goethe conocía (Schafarschik, 2009, p. 74). Gaier, por su parte, considera que este es el motivo principal de Fausto, representado en la obra a través de las dos almas escindidas de su protagonista que son tensionadas por dos tipos de amor diferentes, y que este concepto tiene su base en el Fedro y el Banquete de Platón (Gaier, 2012, p. 149). Para Trunz, sin embargo, es el neoplatonismo del siglo XVI el que mayor incidencia tiene en el pensamiento de Goethe y, sobre todo, en Fausto (Trunz, 1996, p. 518), una idea que también comparte Schöne, quien admite la existencia de una cierta cosmogonía neoplatónica-pansofísta en esta obra (Schöne, 1982, p. 206). Gaier, no obstante, que también apoya la tesis neoplatónica, centra su análisis en la figura de Ficino y afirma que:

Faust ist der Mensch der Renaissance, die das Projekt der Neuzeit begann. Goethe hat sich in dieser Einschätzung offenbar an Marsilio Ficinos Theologia platonica orientiert [...] Ficino oberster anthropologischer Grundsatz lautet: Wir begehren das Gute vor jeglicher Anstachelung durch die Vernunft [...] Daraus leitet sich da Gott das Gute ist, der Drang unserer Seele ab, Gott zu werden, und damit die sieben Modi dieser Bestrebung, die Goethe im Faust offenbar durchspielt und die Ficino im Buch XVI der Theologia platonica darstellt. Da der Appetit zu Gott, den Ficino in seinem Symposion-kommentar ohne Umstände mit dem Eros gleichsetzt, nie auf Erden befriedigt wird, ist der Mensch als einziges Geschöpf nicht in Ruhe und nicht mit dem irdischen Aufenthalt zufrieden (Gaier, 1999, pp. 47-48).

A nuestro juicio, la presencia de Eros como un impulso hacia el bien a través de la belleza se hace aún más evidente si comparamos Fausto con dos de los textos más influyentes, en lo que al amor se refiere, del neoplatonismo renacentista Los heroicos furores, obra de Giordano Bruno, y la Hypnerotomachia Poliphili (El sueño de Polífilo), cuya dudosa autoría se atribuye al fraile dominico Francesco Colonna. De este modo, una comparativa directa con ambos textos nos puede permitir, a nuestro juicio, profundizar e incluso comprender el dilema existencial que caracteriza a Fausto.

\section{LOS AMORES DE FAUSTO}

Para este análisis, partimos del hecho de que Fausto realiza el paso de un tipo de consciencia subjetiva y limitada a otra mucho más amplia y elevada mediante el progresivo despertar de su 
alma a través del amor y la atracción por la belleza. Un despertar paulatino que se encuentra hábilmente representado mediante el recurso simbólico de los tres grandes amores de Fausto y del 'eterno femenino' que cada una de ellas (y a su modo) canalizan: Margarita, Helena y la Mater Gloriosa. Estos encuentros o uniones eróticas representan la reunión simbólica del aspecto receptivo-femenino-anímico de la naturaleza con su aspecto creativo-masculino-inteligible y universal (Faramiñán, 2020, p. 166). En otras palabras, cada una de las relaciones amorosas de su protagonista simboliza la asimilación de los aspectos superiores de su psique con la potencia única que inspira y da vida a la naturaleza. Así, no es de extrañar que Jung viese la trinidad Margarita, Helena y Mater Gloriosa como una unidad, como un 'hilo rojo' mediante el cual Goethe teje el colorido telar de Fausto (Jung, 1985, p. 228). Alexander Dobrokhotov, por otro lado, considera que:

There are only three fundamentally important female characters, which goes for (symbolizes) three stages of the Eternal Feminine: Margarete, Helena and the Mater Gloriosa. The last one is also a protector of Faust. Helen of Troy might be seen as a second step of the incarnation of the anima after Gretchen (Dobrokhotov, 2013, p. 12).

Desde este punto de vista, el arquetipo del 'alma' en Fausto está representado como una esencia que se encuentra dividida en tres partes a merced de su origen divino. Pero, dado que la distancia entre esta esencia y la forma a la que finalmente da vida es gradual, esta 'alma' prístina y uniforme tiene que adaptarse a cada uno de los planos de la existencia de Fausto: el físicosensitivo, el emocional-racional (psíquico) y el espiritual (en el que la inteligencia se presenta como intuición), por lo que ya tenemos los tres planos y su correspondencia con la personalidad de Fausto (Faramiñán, 2020, p.167).

Nuestro protagonista se siente escindido porque siente que al menos dos fuerzas lo arrebatan y lo tensionan en sentido opuesto. Al hacer de puente entre el espíritu y la materia su psique se encuentra sumergida en los planos más groseros de la personalidad, al tiempo que mira hacia el cielo del espíritu con idéntico aplomo. En consecuencia, a medida que Fausto toma consciencia del carácter vacuo e inconstante de sus más bajas aspiraciones, se libera de su impropia servidumbre egoísta y se impulsa a través de la voluntad al servicio denodado hacia los demás (Faramiñán, 2020, p. 168).

Es el 'eterno-femenino' quien rescata a su consciencia del mundo de las limitaciones y de los condicionantes y la transporta a esferas donde, como declama cerrando la obra el coro místico: "Todo lo perecedero no es más que figura. Aquí lo Inaccesible se convierte en hecho; aquí se realiza lo Inefable. Lo ‘eterno-femenino' nos atrae a lo alto” (Goethe, 2014, p. 541).

\section{EROS Y EL 'FUROR HEROICO’}

Por todo ello, en Fausto, el amor, que en sus distintas formas proclama a quien lo percibe la superioridad del espíritu sobre la materia, se presenta ante su protagonista como la única vía de regreso a la realidad, como memoria y reminiscencia de su verdadera esencia. Porque solo el amor es capaz de derrumbar las compuertas que ciñen los límites de lo conocido y lo empujan a traspasar sus propios muros, despertando con ello un 'furor heroico' que debe conducirlo de lo más pequeño a lo sublime.

Este 'furor heroico' es a menudo, en palabras de Giordano Bruno (2011, p. 295), tormentoso, pues al ser un reflejo del amor por lo invisible, por lo sagrado, por el amor a Dios y al destino característico del sabio y del amante juicioso, se manifiesta en el hombre vulgar como un amor que 
es incapaz de vivir en el presente y que tan solo se intensifica con la distancia y la ausencia. Sin embargo, el amor es siempre el mismo, por lo que la diferencia reside en el sujeto que, en el primer caso ha aprendido a considerar las cosas mudables como cosas que no son (Bruno, 2011, p. 296), mientras que el segundo se halla, como Fausto, entre dos mundos. Como los versos de Fausto, que tanto nos recuerdan a los que Bruno pone en boca de Tansilio:

\author{
Dos almas residen, jay! En mi pecho. \\ Una de ellas pugna por separarse de \\ la otra; la una, mediante órganos \\ tenaces, se aferra al mundo en un \\ rudo deleite amoroso; la otra se eleva \\ violenta del polvo hacia las regiones \\ de sublimes antepasados (Goethe, 2014, p. 75). \\ Vacío de esperanzas al infierno llego, \\ y lleno de deseos al cielo me presento: \\ cual eterno sujeto a dos contrarios, \\ echado soy del cielo y del infierno. \\ A mis penas no hay tregua \\ pues en medio de dos veloces ruedas, \\ de un lado para otro, ambas me llevan \\ (Bruno, 2011, p. 298).
}

Como podemos ver, esta comparación es especialmente interesante, pues De los heroicos furores de Bruno es una obra que nos permite definir con gran claridad cuál es papel que Goethe atribuye al amor en Fausto. Tanto para Goethe como para Bruno - probablemente por la influencia platónica y renacentista que en ambos autores tuvo El Banquete de Platón- Eros se presenta como un mediador cuya ambigua naturaleza permite a los seres humanos conectar lo que está arriba con lo que está abajo: "Empezando por las cosas bellas de aquí y sirviéndose de ellas como de peldaños, ir ascendiendo continuamente, en base a la belleza" (Platón, 2008, Banquete. 211c y, en menor medida, Fedro. 245a). El interés de Goethe por Giordano Bruno, en cambio, proviene, según Gray, de su época de estudiante en Estrasburgo y de cuando escribió su Teoría de los Colores (Gray, 1952, pp. 109-110), un texto en el que, para Schöne, puede apreciarse un importante trasfondo metafísico neoplatónico (Schöne, 1987).

Desde este punto de vista platónico y neoplatónico, el 'heroico furor' es todo aquello que impulsa a aspirar a elevarse, a olvidarse de sí mismo y a perseguir incansable la unidad que subyace más allá de toda multiplicidad, como la luz más allá de los colores. Se trata, no obstante, de un proceso irregular y cíclico, tal como podemos constatar en Fausto, donde su protagonista, ahíto de amor a la belleza y escindido entre las cosas del cielo y las de la tierra, va muchas veces, como también relata Bruno (2011, p. 299), de un extremo al otro. Fausto pasa, del amor a la humanidad al comienzo de la obra: "Adormecidos están ahora los ímpetus desordenados, a la vez que toda actividad turbulenta; ahora se hace sentir el amor a la humanidad, se hace sentir el amor a Dios" (Goethe, 2014, p. 78), a la vil recaída del final: "El paraje donde se elevan los tilos, la choza de tinte oscuro, la ruinosa capilla, no son míos. Y si quiero descansar allí, las sombras extrañas me estremecen. Es una espina para los ojos, una espina para los pies" (Goethe, 2014, pp. 507-508).

En cualquier caso, gracias al daímon Eros-Mefistófeles que siempre lo acompaña, el amor es el verdadero motor que lleva a Fausto a pasar por los tres tipos de relaciones eróticas que 
acabamos de mencionar y que coinciden con los tres tipos de amor que también encontramos en Bruno. En primer lugar, el amor a Margarita, ciego, estúpido e irracional, pero que mantiene un atisbo constante de atracción divina que hace que Fausto quiera ser mejor, que desee salir de sí mismo para fundirse con el otro y "abandonarse por completo y sentir un embeleso que ha de ser eterno. ¡Eterno!” (Goethe, 2014, p. 170). En segundo lugar, el amor a Helena, que permite a Fausto obrar acciones admirables y lo lleva a recibir en sí mismo el espíritu y el sentido divino, de suerte que gracias a él "hablará y actuará necesariamente bajo la inspiración de una inteligencia superior" (Bruno, 2011, p. 303). Por último, al final de la obra y bajo un estímulo interior, despierta en él el "amor por la divinidad, la justicia, la verdad y la gloria" (Bruno, 2011, p. 303) a través de la figura de la Mater Gloriosa.

Mefistófeles es quien le señala, tal como hace Diótima con Sócrates en el Banquete, el camino de retorno paulatino y progresivo hacia la luz:

Empezando por las cosas bellas de aquí y sirviéndose de ellas como de peldaños ir ascendiendo continuamente, en base a aquella belleza, de uno solo a dos y de dos a todos los cuerpos bellos y de los cuerpos bellos a las bellas normas de conducta, y de las normas de conducta a los bellos conocimientos, y partiendo de éstos terminar en aquel conocimiento que es conocimiento no de otra cosa sino de aquella belleza absoluta, para que conozca al fin lo que es la belleza en sí (Platón, 2008, Banquete. 211c).

Sin embargo, sin desmerecer el amor por Margarita, es Helena de Troya la que realmente despierta en Fausto el 'furor heroico' y el verdadero amor por la belleza, siendo la primera apenas un reflejo de la segunda: "La bella forma que en otro tiempo me seducía y en mágico reflejo me colmaba de dicha, no era más que una sombra de semejante beldad" (Goethe, 2014, p. 311). Pero, para acercarse a ella, Fausto tiene que renunciar por completo a su vida, sumirse en el profundo sueño de su inconsciente y viajar en el tiempo y el espacio a un lugar donde poder contemplarla directamente y no a través de un espejo; una tierra soñada lejos del mundo de los sentidos donde, para Bruno (2011, p. 310), "no podemos contemplar a Dios sino como en sombra y espejo", pues el héroe es aquel "que trata de obtener una inmensidad, de suerte que se propone un fin allí donde no hay fin" (Bruno, 2011, p. 311).

El amor por Helena representa, por tanto, la integración del mundo racional de Fausto con la inmensidad cognitiva del inconsciente a través de la imaginación, una transformación que lo lleva a convertirse en un héroe y en un ser en el que la falsa dicotomía entre lo que está arriba y lo que está abajo se resuelve mediante la comprensión del movimiento como expresión de lo infinito; un movimiento metafísico que "no va de lo imperfecto a lo perfecto, sino que circunda los grados de la perfección hasta llegar al centro infinito, el cual no es formado ni forma" (Bruno, 2011, p. 321). Fausto percibe cómo "la existencia es un deber, aunque no sea más que un instante" (Goethe, 2014, p. 434), pues gracias a Helena se siente realmente vivo y percibe la infinitud de su ser en el ahora. Sin embargo, su tránsito por la mágica 'Noche de Walpurgis clásica' no es definitivo y Fausto debe regresar de nuevo a su mundo tras haber atesorando la experiencia y el conocimiento adquirido.

En cualquier caso, de su amor por Helena nace Euforión, un ser que, a la manera que Bruno nos indica:

Corre hacia lo que no puede alcanzar, se dirige a donde no puede llegar y quiere abrazar lo que no puede comprender; y siempre aspira a más, pues cuanto más va en vano alejándose del alma, tanto más va inflamándose y perdiéndose en el infinito (Bruno, 2011, p. 320).

Una vez este se desprende de los lazos familiares que lo atan al mundo, libera con ello a su simbólico padre, pues, gracias a Euforión, Fausto comprende que el "Amor; este dios, por merced y 
favor del cielo, tiene el poder de transformarlo en aquella otra naturaleza a la que aspira" (Bruno, 2011, p. 319). Helena se desvanece entonces entre sus brazos y desaparece ante sus ojos al ser integrada por Fausto como parte de sí mismo.

De nuevo la muerte se presenta como una liberación, pues "la muerte es la consigna: esto desde luego se comprende" (Goethe, 2014, p. 449), pero una muerte que es en realidad una transformación, un cambio drástico de perspectiva simbolizado en un portentoso cambio de escenario. Por eso, cuando finaliza la 'Noche de Walpurgis clásica', Fausto ya tiene la capacidad de conquistar el mundo y de percibirlo, no solo a través de sus sentidos, sino de su intelecto, pues gracias a Helena y a Margarita, a quienes contempla en el cielo desde las 'altas montañas' (acto cuarto), comprende que "todo amor procede del ver: el amor inteligible de ver inteligiblemente, el sensible del ver sensiblemente [y que] así como en toda la potencia visiva se encuentra, en forma de aptitud, todo lo visible, así mismo en la potencia intelectual está todo lo inteligible" (Bruno, 2011, p. 325). A raíz de este acontecimiento, Fausto renuncia a su bienestar personal en pos de la política y el buen gobierno, pues comprende que solo mediante la constante acción abnegada y desinteresada puede manifestarse la potencia creadora de la naturaleza en el ser humano: "El hombre que debe mandar ha de sentir en el mando la dicha suprema. Su pecho está lleno de una alta voluntad... será el más encumbrado, el más digno de todos. El goce hace vulgar" (Goethe, 2014, p. 466).

La razón de este cambio de perspectiva es que el mundo de su inconsciente, donde moran las imágenes de sus sueños y temores, ya forma parte de un solo ser donde conviven los contrarios en armónica relación. Fausto es por tanto un hombre nuevo que se encuentra, gracias al amor, en disposición de enfrentar el abismo de la muerte. Ha amado, ha luchado, ha errado, ha conquistado y ha renunciado, en definitiva, ha vivido y ha comprendido (recordado) cuál es la contrariedad de la que es imagen el árbol de la ciencia del bien y del mal. De la oscuridad de su lóbrega buhardilla, con la ayuda de las sombras mefistofélicas, Fausto ha pasado de aspirar a la belleza sensible de Margarita a la inteligible de Helena, para arribar, finalmente, a la belleza divina de la Mater Gloriosa. En palabras de Bruno (2011, p. 373): "Así el espíritu heroico siempre renovará sus tentativas hasta tanto no se vea exaltado al deseo de la hermosura divina en sí misma, al margen de toda similitud, figura, imagen y especie, si es posible; y más todavía, si sabe llegar a tanto". Porque, como anuncian los ángeles del final de la obra: "Aquel que se afana siempre aspirando a un ideal, podemos nosotros salvarle" (Goethe, 2014, p. 536), aunque esa salvación implique lucha, dolor y la superación de diferentes y consecutivos ciclos de éxito y fracaso.

\section{LA HYPNEROTOMACHIA DE FAUSTO}

Lo analizado hasta el momento nos conduce al concepto de la hypnerotomachia, una palabra compuesta en la que se encuentran tres de los elementos más importantes de Fausto: el sueño hypnos, el amor eros y la lucha interior. Algo que nos remite a otra obra no menos significativa cuya relación y paralelismo puede resultarnos muy útil: la Hypnerotomachia Poliphili (1499), atribuida al fraile dominico Francesco Colonna (Kretzulesco-Quaranta, 2005) y traducida recientemente en nuestro idioma como el Sueño de Polífilo por Pilar Pedraza (1981 y 1999). No obstante, como apunta Ana Suárez Miramón (2014, p. 256), "se hace muy difícil pensar que no fuera conocido en nuestro país en el Siglo de Oro”. Su edición prínceps fue publicada en 1499 en una misteriosa mezcla de latín e italiano vulgar, en la imprenta veneciana del editor Aldo Manuzio. 
Se trata de una obra que, a pesar de su origen incierto, obtuvo gran éxito a partir del siglo XVI. Desde Miguel de Cervantes, François Rabelais hasta Julio Verne (pasando por un gran número de autores) la misteriosa influencia de esta obra se ha ido haciendo notar a lo largo de los más de quinientos años de su trayectoria. La base de la historia se apoya en el carácter onírico de las aventuras de Polífilo (etimológicamente 'amigo de todas las cosas') en las que, entre otros avatares, se enamora perdidamente de la ninfa Polia (etimológicamente 'todas las cosas') en el transcurso de un sueño que tiene lugar dentro de otro sueño. El relato consta de dos partes diferenciadas, la primera en la que es Polífilo el narrador y la segunda en la será Polia la que narre su versión de lo ocurrido. La naturaleza mítico-alegórica de la narración, repleta de signos mágicos y de enigmáticas descripciones, ha hecho de ella una obra de culto imprescindible para el lector que quiera profundizar en el sentido mistérico tanto del sueño como de la muerte. Una obra que, en palabras de Pilar Pedraza:

Es uno de los libros más curiosos y desventurados jamás salidos de las prensas: citado por muchos, leído por pocos y vilipendiando por una crítica literaria anacrónica, impaciente y corta de miras desde hace tres siglos, no resulta extraño que mantenga casi intacto el secreto de muchos de sus tesoros (Pedraza, 1981, p. 3).

Con semejante sino no debe resultar extraño que lo utilicemos aquí como ejemplo de paralelismo con Fausto, pues estas palabras bien pueden ser atribuidas a la opera magna de Goethe. Sin embargo, no es esta la única similitud entre ambos textos, toda vez que el afán y la mayor aspiración de sus dos protagonistas es alcanzar la huidiza ilusión de poder 'ser' y poseer aquello de lo que carecen mediante una simbólica lucha de amor en sueños. En esta relación, además, se encuentran y enlazan todas las figuras alegóricas de Fausto de una manera natural, esto es, la imagen alegórica del sueño, la presencia constante y mediadora del amor, la irrupción en otra realidad o universo mágico y la lucha constante por conquistar el derecho a "forzar las puertas ante las cuales todos querrían pasar por alto" (Goethe, 2014, p. 61).

Por otro lado, según Ordine, esta obra también coincide con la que acabamos de analizar en el punto anterior:

La experiencia singular de los Furores podría aproximarse a la Hypnerotomachia Poliphili [...] una lectura atenta de ambos textos podría poner de manifiesto una serie de vínculos conceptuales a partir de una sorprendente 'coincidencia' (Ordine, 2008, p. 128).

Señala como tal el hecho de que la visio in somniis que los caracteriza (y que también encontramos en la segunda parte de Fausto) "no sobreviene, como podría parecer en un primer momento, en el marco de una experiencia irracional, sino que concretiza en un ejercicio racional, en el cual el Rigor y la Voluntad desempeñan un papel importante" (Ordine, 2008, p. 128).

Mutatis mutandis, Fausto también guarda una enorme relación con esta historia tan mágica como misteriosa como es la Hypnerotomachia, pues en ambos relatos la voluntad es precisamente la que permite a sus protagonistas transitar el perfil irregular del camino que lleva: del mundo reglado y conocido de su consciencia, al universo onírico y caótico de su inconsciente, pero sin caer presa de la locura y la peligrosa contradicción que aparentemente existe entre ambas realidades. Cabe, no obstante, hacer una pequeña apreciación respecto al tipo de voluntad que implica este proceso, pues, al estar dirigida hacia el interior del ser humano, no consiste en un tipo de voluntad como la que trata de controlar de forma absoluta los acontecimientos psíquicos a los que se enfrenta cada individuo, sino que es más bien una voluntad de asimilación e integración de la naturaleza salvaje y natural de los mismos a través de un proceso de expansión y transvaloración de los límites 
tradicionales de la psique. En este sentido, la admisión del sueño como el aspecto oculto de la vigilia, como las dos caras de una misma realidad, supone ya de por sí un deslinde evidente de las fronteras culturales de la consciencia y del impulso volitivo.

La similitud entre ambas historias (sobre todo con la segunda parte de Fausto) no parece ser, por tanto, anecdótica, toda vez que ambas comparten una serie de elementos simbólicos de enorme importancia respecto del sueño y la vida que se encuentran presentes en la tradición clásica, en la que ambas se apoyan. Para Jung (1997, p. 34), por ejemplo, "la Hypnerotomachia Poliphili y el Fausto de Goethe han calado hondo en la antigüedad para hallar le vrai mot de la situación. El primero conjuró a la reina Venus, el último a la Helena troyana". De ahí que, relacionando la una con la otra, podamos extraer algunas conclusiones que nos señalan, como en La vida es sueño de Calderón (Méndez, 2000), la naturaleza onírica de la existencia en la tierra, pues tanto Fausto como Polífilo sufren una drástica transformación a merced de su experiencia en un sueño. Un paralelismo que es poéticamente interpretado por Gerald de Nerval en su obra Voyage en Orient:

L'âme fidèle (Polia) ne se faisait pas attendre, et tout l'empire mythologique s'ouvrait à eux de ce moment. Comme le héros d'un poême plus moderne et non moins sublime (Faust), ils franchissaient dans leur double rêve l'immensité de l'espace et des temps ; la mer Adriatique et la sombre Thessalie, où l'esprit du monde ancien s'éteignit aux champs de Pharsale! Les fontaines commençaient à sourdre dans leurs grottes, les rivières redevenaient fleuves, les sommets arides des monts se couronnaient de bois sacrés ; le Pénée inondait de nouveau ses grèves altérées, et partout s'entendait le travail sourd des Cabires et des Dactyles reconstruisant pour eux le fantôme d'un univers. L'étoile de Vénus grandissait comme un soleil magique et versait des rayons dorés sur ces plages désertes, que leurs morts allaient repeupler ; le faune s'éveillait dans son antre, la naïade dans sa fontaine, et des bocages reverdis s'échappaient les hamadryades. Ainsi la sainte aspiration de deux âmes pures rendait pour un instant au monde ses forces déchues et les esprits gardiens de son antique fécondité (Nerval, 1889, p. LXIV).

Por otro lado, aunque en esta misma línea, tenemos el estudio de Kuno Francke en el que afirma encontrar un evidente parecido entre la Hypnerotomachia y el episodio de Helena en Fausto:

Here, as well as there, a boundless veneration for classic ideals forms the underlying sentiment. Here, as well as there, we see a man of flesh and blood moving about in a Word of apparitions. Here, as well as there, the hero finds the goal of his desires in a beautiful woman, with whom he retires to a life of a paradisiac enjoyment. Here, as well as there, his love vanished away, and he finds himself alone again in cold reality (Francke, 1893, p. 122).

Además de lo anterior, Francke (1893, pp. 122-123) establece una serie de similitudes entre el episodio de 'las Madres' de Fausto y algunos de los grabados de la Hypnerotomachia. En particular la imagen en la que Polífilo avanza en un desierto hacia tres puertas en cuyo centro aparece la inscripción Mater Amoris, y el grabado que le sigue, en el que Polífilo se encuentra ante la figura de una vieja matrona. También encuentra un claro paralelismo entre la escena de 'la Mascarada' de Fausto con las imágenes de las procesiones triunfales de la Hypnerotomachia en las que aparecen ricamente ilustradas las figuras de Europa, Leda, Dánae, Baco o Cupido. Finalmente compara la ilustración que pone fin a la Hypnerotomachia —en la que Polífilo aparece junto a Polia entre las nubes - con el encuentro de Fausto y Margarita en las regiones del cielo.

Cabe decir que, para apoyar su argumento, Kuno Francke hace uso de dos fuentes contrastadas: por un lado, una carta entre Goethe y Karl Wilhelm Göttling fechada en Weimar el 30 de junio de 1930 en la que aparece una mención directa a la Hypnerotomachia y, por otro, la relación de afinidad artística que existía entre Goethe y el profesor e historiador del arte de la Universidad de Gotinga Johann Dominicus Fiorillo; una relación que, por otra parte, confirma Claudia Schrapel (1994, p. 306). Parece ser que este último había realizado un pormenorizado estudio sobre la Hypnerotomachia y su autor que, justo en la época en la que Goethe estaba componiendo el 
episodio de Fausto y Helena, fue publicado en el primer volumen de su Keine Schriften artistischen Inhalts (Fiorillo, 1803, pp. 153-188). A mayor abundamiento, Francke (1893, pp. 124-125) también confirma la existencia de pruebas evidentes del paso de Goethe por la biblioteca de la Universidad de Gotinga donde existía un ejemplar de esta obra.

En cualquier caso, a nuestro juicio, hay además otros paralelismos que, sin desmerecer los anteriores, son incluso más significativos e importantes. El primero de ellos es el hecho de que tanto Fausto (en la segunda parte de la obra) como Polífilo parten de una noche insomne y desgraciada en la que el dolor y la amargura, provocados por los estragos del amor mal entendido, han hecho mella en las almas de ambos héroes. Por este motivo, los dos buscan refugio en el letargo reparador del sueño y el olvido que, en los dos casos, comienza con un sol que despunta en el horizonte. Polífilo lo contempla al principio de la Hypnerotomachia a través de la ventana de su aposento: "Febo, saliendo ya de las ondas del Océano, no mostraba aún las ruedas girando por los aires de su carro" (Colonna, 1999, p. 77), mientras que Fausto lo describe con idéntica inspiración al despertar del largo letargo que da comienzo a la segunda parte: "Las puertas de roca rechinan con estrépito, las ruedas de Febo giran chirriando" (Goethe, 2014, p. 241). Una alegoría que recuerda al proemio del poema de Parménides (traducido por Bernabé, 2008) que reproducimos a continuación y que, para Gadamer (1995, p. 106), "quiere evocar el carácter repentino e inmediato de la inspiración".

El eje, en los bujes, emitía un chirrido de siringe, al rojo como estaba (y es que lo urgían, vertiginosas, dos ruedas a uno y otro lado), cuando se apresuraban a escoltarme las hijas del Sol —una vez que atrás dejaron la morada de la Noche - hacia la luz, destocando sus sienes de los velos con sus manos. Allí se hallan las puertas de las sendas de la Noche y el Día y las encuadran dintel y umbral de piedra (Bernabé, 2008, p. 155).

Por eso, tras el amanecer, todo parece comenzar de nuevo para ambos y, aunque las viejas aspiraciones del alma siguen intactas, el dolor parece haberse mitigado lo suficiente como para poder emprender una nueva aventura. También en las dos historias se produce una doble caída en el sueño que, tanto en el caso de Fausto como en el de Polífilo, los lleva a un lugar mágico donde se unen la realidad y el mito. Las imágenes que los dos encuentran en este lugar sacro son la clave de su autoconocimiento, en particular Polífilo conoce a Polia y Fausto a Helena, siendo ambas representaciones simbólicas de la belleza y del alma divina que todo ser humano ha de conquistar. Para Kretzulesco-Quaranta (2005, pp. 71-73), este amor de Polífilo por Polia es, entre otras cosas, una alegoría del amor del filósofo por el conocimiento.

Se debe señalar que tanto Colonna como Goethe derrochan en sus respectivas obras un vasto conocimiento sobre el mundo clásico, por lo que los héroes más antiguos de la humanidad comparten espacio en ambos relatos con todo tipo de figuras mitológicas e incluso religiosas. El acceso a este plano encantado hace que la armonización de los contrarios sea también una seña de identidad compartida por ambos. No en vano las dos obras pueden dividirse en dos partes claramente diferenciadas: la primera y la segunda parte de Fausto y el relato de Polífilo frente a la versión de Polia en el Sueño de Polífilo. Sin embargo, en el caso del sueño de Polífilo el orden es el inverso, de manera que la primera parte de Polífilo se corresponde con la segunda de Fausto y viceversa.

Ambos protagonistas persiguen una imagen de la belleza que ya conocían (aunque en principio no la recuerdan, pues recordemos que Fausto ya había contemplado a Helena en el espejo de la 'Cocina de la bruja' y Polífilo ya estaba enamorado antes de iniciar su onírico viaje), un ideal inalcanzable que solo tras pasar una serie de difíciles pruebas puede ser conquistado. Además, la luz es también para ambos la guía y socorro en los momentos de más honda oscuridad y peligro. 
Porque la unidad de todas las cosas, de la 'divinidad una', es la gran clave del lenguaje inextricable de las dos historias. Basta comparar para ello, como hace Francke, las escenas de tránsito en Fausto ('el reino de las Madres' o 'el pasadizo de Perséfone') con las pruebas de Polífilo que tienen lugar frente al obelisco o a las tres puertas en las que el pasado, el presente y el futuro se unen en honor de "la divina e infinita Trinidad de una sola esencia" (Colonna, 1999, p. 252).

Precisamente en 'el pasadizo de Perséfone', Fausto, al igual que Polífilo, cruza un oscuro corredor para llegar hasta su amada. Desgraciadamente Goethe dejó inconclusa esta escena en la que pretendía incluir un diálogo entre Fausto y Perséfone en el Hades. Sin embargo, ambas escenas recuerdan, a través del recurso del sueño dentro de otro sueño, a las dos muertes simbólicas o nacimientos de las que se hacen eco algunas tradiciones mistéricas y religiosas y que describen el proceso de autodescubrimiento como un trayecto que se hace en varias etapas. Desde este prisma, el primer sueño-muerte representa un primer estadio en el que ambos personajes deben liberarse, a través del olvido, de gran parte de las ataduras que los sujetan a la vida terrena - una especie de purgatorio en el que se desprenden de sus deseos más primarios: el miedo o la sed de vida-. En cuanto al segundo sueño-muerte, en ambas versiones aparece representado con la misma idea del túnel y de la luz, que bien podría suponer el tránsito a un plano más íntimo y profundo de la psique en el que la totalidad del ser se expresa mediante imágenes y alegorías.

A partir de este segundo sueño, los dos se mueven entre la razón, la voluntad y el deseo, entre el consejo de las ninfas Logística (razón) y Thelemia (voluntad o deseo), aunque Polífilo, al contrario que Fausto, no bebe de las aguas del Letheo: "casi fuera de mí, con la inteligencia estupefacta y el apetito adormecido, abrí los dedos que retenían el agua, que cayó al húmedo suelo" (Colonna, 1999 , p. 86), por lo que sus recuerdos permanecen una vez traspasado el umbral. Fausto, en cambio, recupera sus recuerdos cuando se une con Helena y asciende a las 'altas montañas' donde todo su pasado retorna de entre las nubes. Ambos por igual se equivocan, no obstante, en sus primeras decisiones y, en lugar de por el trabajo y la virtud, se deciden por el camino del placer y la concupiscencia. Aunque en los dos casos es su alma quien los socorre con su luz inextinguible mediante el amor que, como tensión opuesta a la fuerza de la gravedad con que la materia aprisiona al ser humano, los libera en la medida en que comienzan a aceptar las consecuencias de sus actos.

Conviene advertir el hecho de que la ninfa Thelemia puede representar, al mismo tiempo, tanto la voluntad como el deseo, por lo que a menudo entra en contradicción con Logística, pues la voluntad puede bien estar al servicio tanto de los deseos como de la razón. En este sentido, es interesante la evolución del término a partir de la Hypnerotomachia mediante la acepción que adopta en la obra de François Rabelais Gargantúa y Pantagruel. En ella, Rabelais hace construir a su gigante Gargantúa una abadía llamada Telema entre cuyos muros solo se ha de cumplir una regla "Haz lo que quieras" (Rabelais, 2011, p. 344). Lo que, junto al emblema que Gargantúa lleva en su sombrero (ágape, amor), llevan a Gabriel Hormaechea a anotar a pie de página que, para Rabelais, Thelemia, Telema, significa “ama y haz lo que quieras” (Rabelais, 2011, p. 345).

El amor, que en las manos del daímon mediador Eros-Cupido, se convierte entonces en las dos historias en una fuerza que no solo une a todas las cosas, sino que además es capaz de mantenerlas unidas. El amor que, para Platón (1992, Crátilo. 398d), guarda una estrecha relación con el concepto de héroe, pues es “del nombre del 'amor' (érôs), del cual nacieron los héroes (héroes)". De hecho, al poder de sus flechas, como al destino, nadie puede escapar, ni siquiera los héroes, el invicto dios Marte, el todo poderoso Júpiter o el mismo Eros, tal como aparece representado en el mito de Eros y Psique de Apuleyo (1995, pp. 133-187). Tampoco Mefistófeles escapa a su influencia cuando contempla a los hermosos querubines divinos en la 'Sepultura'. Por eso Eros-Cupido, al igual que 
Mefistófeles, es el incitador a la acción y al impulso creativo que, a través de la imaginación, retira los velos de la memoria del alma para que el ser humano pueda recordar su verdadero origen. En palabras de Jung, este impulso creativo que es propio del poeta, a menudo:

It is a primordial experience which surpasses man's understanding [...] It arise from timeless depths; it is foreign and cold, many-sided, demonic and grotesque [...] it bursts asunder our human standards of value and of aesthetic form. [...] the primordial experiences rend from top to bottom the curtain upon which is painted the picture of an ordered world, and allow a glimpse into the unfathomed abyss of what has not yet become. [...] Shaping - re-shaping — The eternal spirit's eternal pastime. [...] We find such vision in the second part of Faust and in the Hypnerotomachia of the monk Francesco Colonna (Jung, 1985, p. 221).

De este modo, las ninfas Cinosia (movimiento), Indalomena (imaginación) y Mnemosyne (memoria), de manera respectiva, son las encargadas de correr las cortinas de la galería que conduce a Polífilo ante la majestad de la reina Eleuterilide (libre albedrío). Algo que concuerda perfectamente con lo analizado hasta este momento respecto de Fausto.

Cabe aclarar que para que esta memoria atávica del alma se active, en ambas obras se establece el requisito de que el sujeto explore previamente todos los rincones de su ser más interno. La razón de ello es que las dos composiciones parten de la premisa de que la inversión de la vida como sueño solo es perceptible por aquellos que ya se han trascendido a sí mismos y cuya consciencia se encuentra lo suficientemente despierta como para ser capaces de ver el bosque más allá de los robustos troncos de los árboles que lo componen. Como no todos los seres humanos se encuentran en ese punto de desarrollo, pues la mayoría no son capaces de traspasar las fronteras del sueño y de la muerte sin beber de las aguas del Letheo, el olvido les mantiene en el error de que la verdadera vida es la que les sorprende al despertar cada mañana. Además, como durante la noche sus sueños se alimentan únicamente de sus miedos y frustraciones, su posibilidad de percibir — como Polífilo o Fausto- la sobria belleza del alma se ve reducida y constreñida al quedarse adherida a las ataduras de su personalidad. Como resultado, con cada aurora despiertan en la ilusión de un nuevo día que, con sus luces y sus desdibujadas sombras, disipa los posibles recuerdos de la noche, los terrores de la soledad y vuelve a ocultar, un día más, los recónditos secretos del espíritu bajo la pálida máscara del escepticismo y la incredulidad.

Algo similar les ocurre a Polífilo y a Fausto al final de su aventura, pues tanto Polia como Helena terminan por desaparecer ante la atónita mirada de sus amantes que, incapaces de reconocerlas, las contemplan por última vez mientras se desvanecen entre los dedos de sus manos.

Y suspirando, aquella imagen celeste semejante a una diosa se disolvió en el aire entre un vapor de fragancia desconocida, como una espiral de humo de ámbar y almizcle que se eleva, oloroso, en el aire con gran placer de los espíritus celestes, y desapareció de mis ojos rápidamente junto con el sueño delicioso, diciéndome: 'Adiós, Polífilo, querido mío que tanto me has amado' (Colona, 1999, pp. 721-722).

\section{CONCLUSIONES}

De lo analizado se desprende que el carácter simbólico del arquetipo de lo femenino en Fausto (el 'eterno femenino') es una metáfora del alma que anhela ser encontrada y que es la que verdaderamente impulsa al ser humano a elevarse siempre a cotas más altas. Esta imagen arquetípica del alma, como apuntábamos al comienzo de este trabajo, ya aparece de manera evidente en Platón, aunque es sobre todo Plotino (1985, Enéadas. III. 5. 8. 10) quien la desarrolla, y es la filosofía neoplatónica del Renacimiento la que la va a reproducir en campos tan diversos como 
el arte y la literatura. Así, a partir del siglo XVI, los mitos griegos recobran una vez más su antiguo esplendor en imágenes y relatos en los que el carácter inteligible de la divinidad es encarnado por héroes y dioses varones, mientras que el anímico-alegórico se encuentra oculto tras el perfil alegórico de las divinidades femeninas.

No es extraño entonces que, en los dos textos de referencia, De los heroicos furores y la Hypnerotomachia Poliphili, se cumpla esta regla y que su influencia en Fausto nos permita analizar esta obra desde un punto de vista psicológico. En los dos primeros, los personajes femeninos encarnan al mismo tiempo los tres aspectos antes descritos: el plano anímico-físico o fisiológicoinferior, el psíquico-intermedio y los aspectos superiores de la psique, mientras que, en Fausto, cada plano está representado mediante un personaje femenino diferente. De este modo, para entender esta obra, se debe de tener en cuenta que la diferencia entre los dos primeros planos radica, según Jung, en que:

Ambos son fenómenos vitales, pero se distinguen en que aquella parte de la función que es designada como parte inferior tiene un aspecto fisiológico innegable. Su existencia e inexistencia parece ligada a las hormonas. Su funcionamiento tiene carácter compulsivo; de esto proviene la designación 'impulso' (Jung, 1997, p. 126).

Y que la diferencia entre el plano psíquico-intermedio y el superior surge:

Cuando deslindamos entre lo psíquico y la esfera de los instintos, estableciendo en cierta medida un límite inferior, se impone un deslinde similar por arriba. Con la creciente liberación de lo meramente instintivo, la parte superior alcanza finalmente un nivel en el cual en algunos casos la energía inherente a la función no solo no está orientada en el sentido primitivo del impulso, sino que llega a poseer una forma que es denominada espiritual (Jung, 1997, p. 127).

Por lo tanto, en Fausto, lo que generalmente se denomina alma es únicamente el aspecto psíquico e intermedio de una unidad aún mayor por conquistar y que se manifiesta a través de tres formas diferentes dependiendo del plano en el que se proyecte, esto es: un alma sensitiva, un alma racional y un alma intelectiva que no desciende jamás y a la que Fausto debe acercarse. Como ha quedado de manifiesto, estas tres expresiones de un mismo ser están perfectamente representadas en esta obra a través de los distintos amores de Fausto: la prístina e inocente Margarita, la bella y arquetípica Helena, y la inefable Mater Gloriosa con la que termina la obra.

A su vez, cada una de ellas son encarnaciones de los distintos tipos de conocimiento a los que puede acceder el ser humano y que, en palabras de Kerényi (2010, p. 26), "el alma guarda como su tesoro más concerniente", pues solo es accesible mediante una unión sagrada en la que la potencia del alma "se muestra efectiva y poderosa". De esta manera, Fausto asciende al conocimiento como por una escala, a medida que integra los aspectos ocultos de su alma y comprende, al llegar a la cima de sí mismo, que es allí donde se encuentran las respuestas a todas sus preguntas.

\section{Bibliografía}

Apuleyo, Lucio, El asno de oro, Madrid, Editorial Gredos, 1995.

Bernabé, Alberto, Fragmentos Presocráticos, de Tales a Demócrito, Madrid, Alianza Editorial, 2008.

Bruno, Giordano, Expulsión de la bestia triunfante/De los heroicos furores, Madrid, Editorial Siruela, 2011.

Colonna, Francesco, Sueño de Polífilo. Tomo Primero, Valencia, Comisión de Cultura del Colegio Oficial de Aparejadores y Arquitectos Técnicos de Murcia, 1981.

Colonna, Francesco, Sueño de Polífilo, Barcelona, Editorial Acantilado, 1999. 
EL AMOR, LA BELLEZA Y EL 'ETERNO FEMENINO’ EN EL FAUSTO

Dobrokhotov, Alexander, “The short happy life of Goethe's Faust, or hieros gamos as the center of the tragedy", en Basic reseach program. Working Papers. (Series: Humanities WP BRP 15/HUM/2013, Moscow, National Research University Higher School of Economic, 2013.

Faramiñán Fernández-Fígares, Juan Manuel de, El Fausto de Goethe. Análisis simbólico y filosófico, Granada, Editorial Comares, 2020.

Fiorillo, Johann Dominicus, "Ueber den Dominicaner Francesco Colonna, und sein berühmtes Buch Hypnerotomachia”, en Fiorillo, J., Kleine Schriften artistischen Inhalts. Göttingen, Heinrich Dieterich Verlag, 1803.

Francke, Kuno, "Did the Hypnerotomachia Poliphili influence the second part of Faust?", en Studies and notes in philology and literature. Vol. II, Boston, Modern language departments of Harvard University, 1893.

Gadamer, Hans Georg, El inicio de la Filosofía Occidental, Barcelona, Ediciones Paidós Ibérica, 1995.

Gaier, Ulrich, Johann Wolfgang Goethe, Faust-Dichtungen, Band 2, Kommentar I, Stuttgart, Philipp Reclam jun, 1999.

Gaier, Ulrich, Lesarten von Goethes Faust, Konstanz, Eggingen: Edition Isele, 2012.

Jung, Carl Gustav, “Psychology and Literature”, en Ghiselin, B., The Creative Process: A Symposium, Berkeley, University of California Press, 1985.

Goethe, Johann Wolfgang, Fausto, Madrid, Alianza Editorial, 2014.

Goethe, Johann Wolfgang, Poesía y Verdad, Barcelona, Editorial Alba, 2017.

Gray, Roland, Goethe the Alchemist, New York, Cambridge at the University Press, 1952.

Jung, Carl Gustav, Arquetipos e inconsciente colectivo, Barcelona, Editorial Paidós, 1997.

Kerényi, Károly, Imágenes primigenias de la religión griega (Misterios de los Cabiros III), Madrid, Editorial Sexto Piso, 2010.

Kretzulesco-Quaranta, Emmanuela, Los jardines del sueño. Polífilo y la mística del Renacimiento, Madrid, Editorial Siruela, 2005.

Kristeller, Paul Oskar, The Philosophy of Marcilio Ficino, New York, Columbia University Press, 1964.

Méndez, Sigmund, El mito Fáustico en el drama de Calderón, Kassel, Edition Reichenberger, 2000.

Nerval, Gerald de, “Introduction a un ami (Vers l'orient)”, en Nerval, G., Voyage en Orient. Tome premier, Paris, G. Charprentier et Cle Éditeurs, 1889.

Ordine, Nunccio, El umbral de la sombra. Literatura, filosofía y pintura en Giordano Bruno, Madrid, Editorial Siruela, 2008.

Pedraza, Pilar, "Introducción, comentarios y notas", en Colonna, F., Sueño de Polífilo. Tomo Primero, Valencia, Comisión de Cultura del Colegio Oficial de Aparejadores y Arquitectos Técnicos de Murcia, 1981.

Platón, Diálogos II (Gorgias, Menéxeno, Eutidemo, Menón, Crátilo), Madrid, Editorial Gredos, 1992.

Platón, Diálogos III (Fedón, Banquete, Fedro), Madrid, Editorial Gredos, 2008.

Plotino, Enéadas III-IV, Madrid, Editorial Gredos, 1985.

Rabelais, François, Gargantúa y Pantagruel (Libro Primero), Barcelona, Editorial Acantilado, 2011.

Rotten, Elisabeth, Goethes Urphänomen und die plantonische Idee, Gießen, Verlag von Alfred Töpelmann, 1913.

Schafarschik, Von Walter, Lektüreschlüssel für Schülerinnen und Schüler, Johann Wolfgang Goethe Faust II, Stuttgart, Philipp Reclam jun, 2009.

Schöne, Albrecht, Götterzeichen, Liebeszauber, Satanskult, München, Verlag C.H. Beck, 1982.

Schöne, Albrecht, Goethes Farbentheologie, München, Verlag C.H. Beck, 1987. 
Schrapel, Claudia, "Fiorillos Sicht der altdeutschen Kunst und ihre Interdependenzen mit der Kunst und der Kunstbetrachtung des frühen 19. Jahrhunderts", en Middeldorf Kosegarten, A., Johann Dominicus Fiorillo. Kunstgeschichte und die romantische Bewagung um 1800, Wallstein Verlag, 1994.

Suárez Miramón, Ana, "Cervantes y el sueño de Polífilo", en Martínez, E. y Fernández, M.: Comentarios a Cervantes, Actas selectas del VIII Congreso Internacional de la Asociación de Cervantistas, Oviedo, Fundación Mํㅡㄹ Cristina Masaveu Peterson, 2014.

Trunz, Erich, Goethe-Faust, Kommentiert von Erich Trunz, München, Verlag C.H. Beck, 1996. 